\title{
The choice of appropriate generator systems to enhance the renewable energy share in buildings. A comparison between PV-assisted heat pumps and biomass boilers
}

\author{
Roberto Bruno ${ }^{l}$, Piero Bevilacqua ${ }^{l}$, Stefania Perrella $^{l}$, Daniela Cirone $^{l}$, and Natale Arcuri ${ }^{1}$ \\ ${ }^{I}$ Mechanical, Energy and Management Engineering Department - University of Calabria, P. Bucci 46/C -87036 - Rende (CS) - Italy
}

\begin{abstract}
Low-energy buildings are generally equipped with generation systems driven by renewable sources. Regarding heating and DHW production, two choices appear appropriate: PV assisted heat pumps and biomass boilers. In this paper, by means of TRNSYS dynamic simulations, the non-renewable primary energy was determined for two buildings located in different climatic contexts by varying the PV size to consider the actual self-consumed electricity of commercial devices. Results showed that in cold climates biomass boilers are more suggested, especially in unfavourable climatic zones, whereas the COP of airwater heat pumps is strongly penalized by the outdoor temperatures and in many cases the self-consumed PV electricity does not limit the grid intervention adequately. However, in building with limited thermal energy demands and in favorable climates, suitable PV sizes make heat pumps more performant than biomass boilers. The same calculations were conducted with the quasi-steady approach, in accordance with the Italian building energy certification procedure, observing a favorable scenario in a heating plant equipped with a PV assisted heat pump because it assumes the renewable electricity entirely absorbed, while the accounting of the actual self-consumed share produces a greater demand of non-renewable energy.
\end{abstract}

\section{Introduction}

Because in recent years the issue related to the global warming caused by the use of fossil fuels have increased, it has become mandatory to expand the use of renewable energy source in the building sector. Indeed, currently the world housing account for 2,109,205 thousand tons of oil equivalent of consumed energy ( $21.2 \%$ of total energy consumption), with a correspondent amount of $\mathrm{CO}_{2}$ emission of 2033 Mton per year [1]. For this purpose, in Europe the promulgation of the Directive 28/2009/CE has promoted the use of renewable energy in the building sector to reduce the percentage of $40 \%$ on the final energy consumption that contributes for the $36 \%$ of GHG emissions [2]. Recently, in October 2020 the regulation amending the Energy Performance of Buildings Directive (2018/844/EU) has introduced new targets as part of the so-called "European Green Deal", by presenting an action plan with concrete regulatory, financing and promoting measures to boost the penetration of renewable technologies in the building sector [3]. Among the several generation systems employed in residential buildings for heating and DHW production purposes, electric heat pumps assisted by PV generators and biomass boilers are able to allow a rational exploitation of the renewable sources [4]. Indeed, the firsts use the renewable energy contained in the air, water or ground to supply appropriate emitters for the air-conditioning and to produce Domestic Hot Water (DHW) by absorbing electricity from the grid, that could be properly limited by the selfconsumed PV electricity [5,6]. Biomass boilers, instead, benefit of the neutral $\mathrm{CO}_{2}$ emission that allows for considering the majority of the embodied primary energy as fully renewable [7]. Consequently, it is interesting to compare these generations systems in terms of exploited renewable energy, in order to determine how they act on the limitation of the fossil primary energy and on the external environment.

The comparison is justified by the fact that modern biomass boilers have performance indexes considerably lower than those detectable in heat pumps, therefore they could seem naturally penalized. On the other hand, in heat pumps the advantage could be largely counterbalanced by the electricity absorbed from the grid, whose conversion factor required to quantify the fossil primary energy share is almost 10 times greater than that employed in biomass boilers [8]. Moreover, when heat pumps use the outdoor air as thermal source, the absorbed electricity strongly depends on the external temperature levels [9], therefore the actual performances have to be evaluated in different climatic contexts. 
A preliminary comparison between biomass boilers and heat pumps was conducted in [10] in which authors compared the generation systems exclusively in economic and environmental terms for small-detached houses located in Poland. They determined that the operating cost savings of the heat pump did not compensate the large installation costs in an acceptable period, moreover the $\mathrm{CO}_{2}$ emission level were larger than biomass boilers. In [11], heat pumps and biomass boilers were analyzed in terms of LCA, in order to compare these generation systems with the other available for tertiary buildings. Biomass boilers and other devices supplied by fossil fuels were compared in [12], whereas the limitations of air-water heat pumps in cold climate was deeply investigated in [13].

Some studies suggest to use rationally the rejected heat from biomass boilers as thermal source for heat pumps in hybrid systems [14], whereas no studies were found to compare the renewable primary energy share attainable in different plant configurations equipped with these devices. Therefore, regarding heating and DHW production, in this paper the generation systems were compared in terms of non-renewable primary energy by referring to two different buildings located in different climatic zones of the Italian territory. In particular, the buildings have different thermal energy requirements, whereas the PV size was varied in presence of heat pumps to quantify the benefits that could be achieved in terms of reduction of the electricity absorbed from the grid. Dynamic simulations of the building-plant systems were conducted in TRNSYS to determine in detail the electricity absorbed by a commercial air-water heat pump as function of the sources temperature and of the operation in part-load mode [15]. Furthermore, for the renewable electricity, it was assumed to give the priority to drive the generation systems, whereas the remaining part to supply internal appliances and the surpluses used to charge a thermal storage system or transferred to the grid. Regarding the biomass boilers, the primary energy was determined by varying the device efficiency as a linear function of the capacity ratio, in accordance with values listed in commercial datasheets. In the considered climatic zones, the simulated buildings are the same from the geometrical point of view whereas the thermal characteristics of the dispersing elements were changed in function of heating degree-day (HDD). Specifically, the insulation thickness in opaque walls was increased whereas the thermal transmittance of the windowed surfaces was reduced with the HDD growth, in order to meet the national regulations in terms of minimum energy performance requirements for new buildings [8].

The same calculations were repeated by adopting the quasi-steady approach [16-18], because currently in Italy it is used for the building energy certification and often used as a reference to establish building energy performances, allowing also to quantify the deviances between the results provided by dynamic and simplified procedures.

\section{Material and Method}

\subsection{Buildings description}

Energy evaluations were conducted by dynamic simulations carried out in TRNSYS on the detached houses of Fig. 1, with gross surface on the ground of $100 \mathrm{~m}^{2}$ and net heated surfaces equal to $57.7 \mathrm{~m}^{2}$ and $115.4 \mathrm{~m}^{2}$ respectively for the single-storey and the double-storey building. The first structure represents a modular unit and the second building was designed by superimposing two modular units, so that the aspect ratio (ratio between the gross dispersing surface $\mathrm{S}$ and gross heated volume V) is equal to respectively $0.75 \mathrm{~m}^{-1}$ and $0.625 \mathrm{~m}^{-1}$. The first was simulated in TRNSYS with a single air node (ground floor), whereas for the second one two air nodes (ground and first floor) have been used and connected to the same generation system [19]. Both the buildings have the same Window to Wall Ratio (WWR) on each exposure, equal to $13 \%, 10 \%$ and $4 \%$ for North/South, East and West [20]. Internal gains (332 W per floor, whose $50 \%$ is radiative) $[21,22]$ and natural ventilation ( 0.5 air-change per hour) were set in accordance to Italian standards. These structures, in fact, have been thermally designed in order to meet the minimal energy requirements regulated by the national legislation [8]. In particular, the following aspects were imposed:

a) mean global thermal exchange coefficient of the envelope lower than a specific threshold, the latter defined as function of the building aspect ratio and the HDD;

b) heating and cooling thermal requirements lower than the correspondent values determined for a reference building with the same geometry but with different envelope thermal parameters;

c) mean seasonal global efficiency for the heating and the DHW systems greater than a limit value, the latter determined as function of heating and DHW plants and of the heat generators features;

d) global primary energy requirements, determined as sum of the correspondent terms for heating and DHW, lower than the correspondent value for the reference building including the share provided by renewable systems;

e) $50 \%$ of the domestic hot water produced by a renewable system;

f) $2 \mathrm{~kW}_{\mathrm{p}}$ of installed PV per $100 \mathrm{~m}^{2}$ of gross surface area on the ground.

Because in the parametric study the number of HDD changes, the respect of the points a), b) and d) has imposed the variation of the insulation thickness (EPS, $\lambda=0.041 \mathrm{~W} / \mathrm{mK}$ [23]) inside the dispersing opaque surfaces (vertical walls, ground floor and flat roof) and the change of the windows thermal transmittances $\left(U_{w}\right)$ and of the normal solar factor $(g \perp)$, in accordance with the values listed in Tab. 1. It can be noted that the buildings were located in five different climatic zone, uniformly distanced by about 500-550 HDD. 

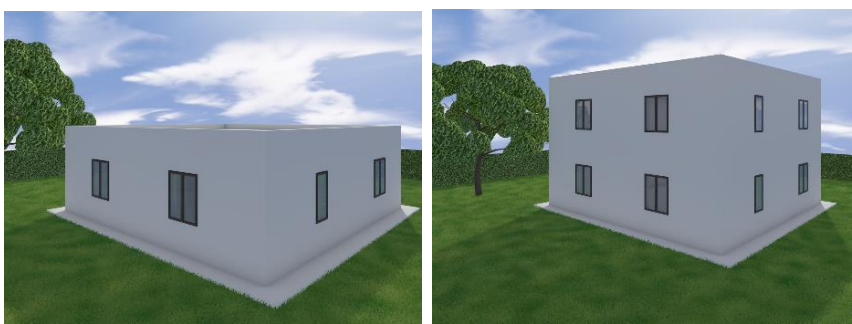

Fig. 1- Perspective views of the single-storey and double-storey building involved in TRNSYS simulations

Tab. 1 - Insulation thickness in dispersing opaque walls and windows thermal transmittance set in the simulated buildings, as function of the climatic zone

\begin{tabular}{|c|c|c|c|c|}
\cline { 2 - 5 } \multicolumn{1}{c|}{} & \multicolumn{3}{c|}{ EPS Insulation thickness $[\mathrm{mm}]$} & $\mathrm{U}_{\mathrm{w}}\left[\mathrm{W} / \mathrm{m}^{2} \mathrm{~K}\right]$ and $\mathrm{g} \perp[-]$ \\
\hline HDD & Ground floor & Flat roof & Vertical walls & Windows \\
\hline 772 & 60 & 80 & 50 & $1.69-0.66$ (low- $\varepsilon$ double pane) \\
\hline 1317 & 60 & 90 & 100 & $1.69-0.66$ (low- $\varepsilon$ double pane) \\
\hline 1861 & 100 & 110 & 100 & $1.69-0.66$ (low- $\varepsilon$ double pane) \\
\hline 2394 & 110 & 140 & 130 & $1.40-0.70$ (clear triple pane) \\
\hline 2897 & 110 & 140 & 130 & $1.40-0.70$ (clear triple pane) \\
\hline 3445 & 120 & 160 & 160 & $1.1-0.62$ (low- $\varepsilon$ triple pane) \\
\hline
\end{tabular}

The localities with the HDD listed in Tab. 1 have the position depicted in Fig. 2; it can be appreciated that these have more or less similar latitudes in order to attain similar PV producibility, between $1300-1400 \mathrm{kWh} / \mathrm{kW}_{\mathrm{p}}$ assuming a polycrystalline technology $[24,25]$. The PV generator is facing South and tilted of $30^{\circ} \mathrm{C}$, made of modules with main electric data listed in Tab. 2. The size of the PV was varied between $2 \mathrm{~kW}_{\mathrm{p}}$ (required minimum installed peak power) to $6 \mathrm{~kW}_{\mathrm{p}}$ (to avoid three-phase installations). The remaining components of the PV plant have been considered in simplified way by setting a BOS (Balance of System) efficiency of 0.85 throughout the year.

Regarding the DHW production, the required water flow rate was determined as function of the net plan surface, in accordance to Italian standard [17], obtaining 100 and 172 liters per day respectively for the single and the double-storey building, and scheduled at daily level as indicated in Tab. 3. For the weather data, TMYs were used and simulations were conducted for the whole year with a timestep of $0.125 \mathrm{~h}$, setting a continuous functioning situation of the heating plant in order to compare the TRNSYS results with those provided by the quasi-steady procedure.

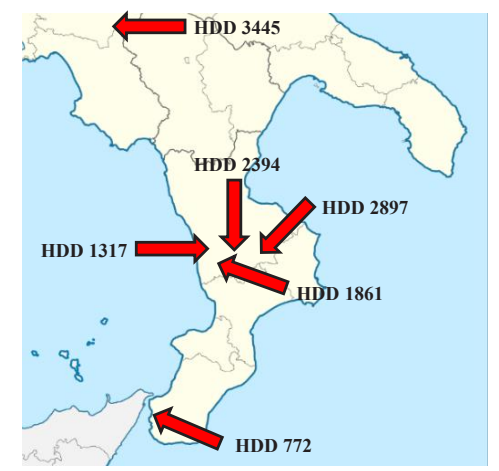

Fig. 2 - Position of the considered localities considered for the buildings energy performance analysis

Tab. 2 - Main electric features of the polycrystalline PV panels considered in simulations

\begin{tabular}{|c|c|}
\hline Short-circuit current at STC & $9.17 \mathrm{~A}$ \\
\hline Current at max power point in STC & $8.80 \mathrm{~A}$ \\
\hline Open-circuit voltage in STC & $35.17 \mathrm{~V}$ \\
\hline Voltage at max power point in STC & $28.49 \mathrm{~V}$ \\
\hline Temperature coefficient of short-circuit current & $0.0052 \mathrm{~A} / \mathrm{K}$ \\
\hline Temperature coefficient of open-circuit voltage & $-0.0081 \mathrm{~V} / \mathrm{K}$ \\
\hline
\end{tabular}


Tab. 3 - Scheduled water flow rate (in liters per hour) requirements for the calculation of the annual DHW energy needs in the considered buildings

\begin{tabular}{|c|c|c|c|c|c|c|c|}
\cline { 2 - 7 } \multicolumn{1}{c|}{} & \multicolumn{9}{c|}{ DHW flow rate (1//) } \\
\cline { 2 - 8 } & $00: 00-$ & $07: 00-$ & $10: 00-$ & $12: 00-$ & $14: 00-$ & $18: 00-$ & $21: 00-$ \\
& $07: 00$ & $10: 00$ & $12: 00$ & $14: 00$ & $18: 00$ & $21: 00$ & $00: 00$ \\
\hline Single-storey & 0 & 12.5 & 0 & 12.5 & 0 & 12.5 & 0 \\
\hline Double-storey & 0 & 21.5 & 0 & 21.5 & 0 & 21.5 & 0 \\
\hline
\end{tabular}

\subsection{Heating plant with the air-water heat pump}

The heating plant is equipped with a commercial and modulating air-water heat pump (AWHP), and the produced hot water supplies a radiant floor inside every thermal zone whose indoor temperature is regulated by a thermostat with a dead band of $1{ }^{\circ} \mathrm{C}$ and a set-point of $20^{\circ} \mathrm{C}$. The cut-off temperature of the heat pump is $-20^{\circ} \mathrm{C}$, with thermal power and the coefficient of performance trends showed in Fig. 4a as function of the outdoor air temperature, by setting the set-point water temperature to $45^{\circ} \mathrm{C}$. Preliminary simulations have allowed for determining the size of the air-water heat pump, by choosing as nominal power the value with the highest frequency detected during the heating period. Thermal powers of about $4 \mathrm{~kW}$ and $8 \mathrm{~kW}$ respectively for the single and the double-storey building were determined, so two commercial airwater heat pumps, with a minimum modulation factor of $30 \%$, were identified and simulated. Among the different climatic zones, it is worth noting that the nominal power values remain almost the same because the increase of the envelope insulation allowed for compensating the thermal losses detectable with the HDD growth, mantaining similar design loads. Radiant floors were implemented in TRNSYS with a pipe spacing of $25 \mathrm{~cm}$, an internal diameter of $10 \mathrm{~mm}$, embedded in a lightweight concrete layer thick $9 \mathrm{~cm}$. The AWHP thermal plant was simulated by considering a vertical tank of $3 \mathrm{~m}^{3}$ as thermal storage system equipped with an electric resistance as backup, maintained at a set-point temperature of $40^{\circ} \mathrm{C}$ for a rational exploitation of the AWHP and to manage PV surpluses rationally (see Fig. 3). Indeed, the control system activates the heat pump also when heating loads are not required if the tank temperature is lower than the set-point and the PV electricity is available. The inlet temperature in the radiant floors was set constant to $35^{\circ} \mathrm{C}$, by implementing a motorized 3-way valve that recirculate a fraction of the returning water flow rate from the same emitters. The latter was always retained supplied by the grid, in accordance with national regulation that hinders the electricity used by Joule effect to be covered by the PV production [8].

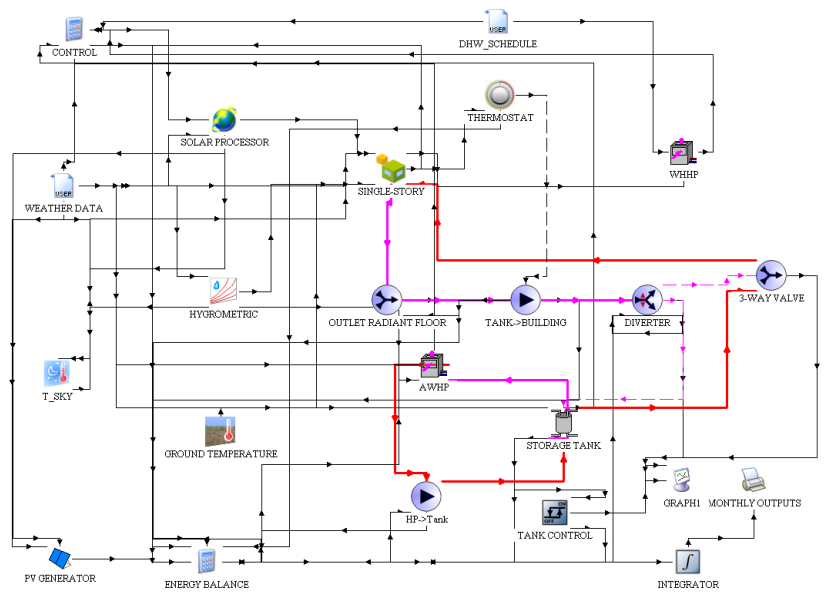

Fig. 3 -Project implemented in the TRNSYS interface for the building-plant system with the AWHP

It is worth noting that the TRNSYS model employed to simulate the AWHP determines the electric consumptions by considering the COP variation with the temperature sources, assuming a full load operation. Actually, the presence of the storage tank determines noticeable functioning times in part load mode, therefore the performance index is further modified when the heat pump capacity ratio (CR) is lower than minimum modulation factor $(30 \%$ in accordance with datasheet). In order to consider this aspect, a further correction factor $f_{c}$ was introduced to determine an actual COP in part-load mode by means of the relation:

$$
C O P_{\text {real }}=f_{c} \cdot \operatorname{COP}_{\text {NOM }}\left(t_{\text {oa }}, 45^{\circ} \mathrm{C}\right) \quad \text { if } C R<30 \%
$$


in which the nominal COP was determined by TRNSYS as function of the outdoor air temperature ( $\mathrm{t}_{\mathrm{oa}}$ ) and by the setting the supplied water flow rate at a temperature of $45{ }^{\circ} \mathrm{C}$. The correction factor, instead, was calculated by a TRNSYS equation for every timestep $t$ in accordance with the procedure described in the EN 14825 [25]:

$$
f_{c}(t)=\frac{C R(t)}{1-C_{c}+C_{c} \cdot C R(t)}
$$

in which $C_{c}$ is the device degradation factor set to 0.9 , as suggested by the standard when manufacturer does not provide pertinent information. Regarding the capacity ratio, it was calculated as:

$$
C R(t)=\frac{P_{h, \text { real }}}{P_{h, N O M}\left(t_{o a}, 45^{\circ} \mathrm{C}\right)}
$$

namely the real thermal power provided by the AHWP to the storage tank and the thermal power that the heat pump could produce in nominal condition when the outdoor air temperature value is toA and the water flow rate temperature is $45^{\circ} \mathrm{C}$. Therefore, Eq. (2) was implemented inside TRNSYS to determine the real COP in accordance to Eq. (1), and successively used to quantify the actual electric consumptions starting from the real provided thermal power.

Regarding the DHW production, an independent water heater heat pump (WHHP) equipped with an electric booster and with performance depicted in Fig. $4 \mathrm{~b}$, assuming DHW at $55^{\circ} \mathrm{C}$, was simulated. Again, for the same reason discussed for the AWHP, the electric energy of the WHHP booster was considered completely absorbed from the grid. The correction of the COP described by Eq. (1) was not implemented, assuming a functioning always in full load mode.

The produced renewable electricity was considered to operate the AWHP and WHHP electric demands, excluding backup and booster systems, and to drive the hydronic pumps. So, the global electric energy absorbed from the grid determined the non-renewable primary energy, by applying a conversion factor of 1.95 as indicated by Italian rules [8].
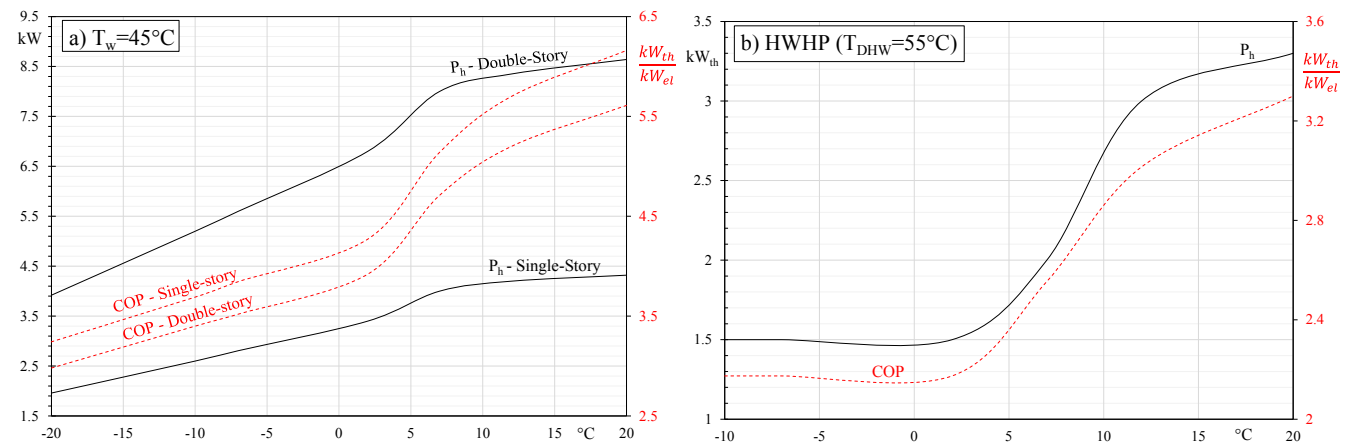

Fig. 4 - Trends of the thermal power and COP as function of the outdoor air temperature in nominal conditions for: a) AWHP $\left(\mathrm{T}_{\text {cut, off }}=-20^{\circ} \mathrm{C}\right)$ b) WHHP $\left(\mathrm{T}_{\text {cut,off }}=-10^{\circ} \mathrm{C}\right)$

\subsection{Heating plant with the biomass boiler}

Regarding the heating plant equipped with a boiler supplied by solid biomass, a commercial device with a burner working with a forced air system, supplies directly radiators by a water flow rate at a constant temperature of $80^{\circ} \mathrm{C}$, in accordance with the plant scheme depicted in Fig. 5. Again, a zone thermostat controls the indoor air temperature with a dead band of $1{ }^{\circ} \mathrm{C}$ and a set-point of $20^{\circ} \mathrm{C}$. The biomass boiler has a combined functioning, therefore the same device is used to provide heating and DHW, but exclusively in winter. In order to cover the DHW demand in summer and to respect the constrain to produce at least the $50 \%$ by means of a renewable system [8], the buildings were equipped with $4 \mathrm{~m}^{2}$ of plane solar thermal collectors with selective surfaces, including a storage tank of $0.5 \mathrm{~m}^{3}$ operating by natural circulation. The building-plant system involves a $2 \mathrm{~kW}_{\mathrm{p}}$ of PV panels (minimum required peak power), whose electricity was used to meet auxiliary consumptions, mainly represented by the hydraulic pumps and the fan of the biomass boiler. In simulations, the energy input in the generation system was computed by considering a boiler efficiency depending on the capacity ratio, by means of the linear relation (determined by interpolating the datasheet values): 


$$
\eta_{t h}=0.0769 \cdot C R+0.8431
$$

that provides a value of 0.92 in nominal conditions $(\mathrm{CR}=1)$ and of 0.86 at the minimum modulation factor $(\mathrm{CR}=0.22)$. Regarding the fan consumptions, the absorbed electric power was determined by the formula:

$$
\dot{Q}_{\text {el, boiler }}=-325.8 \cdot C R^{2}+730.8 \cdot C R+15
$$

that produces an consumption of $420 \mathrm{~W}$ in nominal conditions, of $160 \mathrm{~W}$ at the minimum modulation factor and $15 \mathrm{~W}$ with a switched-off burner. The boiler capacity ratio was calculated as:

$$
C R(t)=\frac{P_{b, r e a l}}{P_{b, \text { NOM }}}
$$

namely the ratio between the actual produced thermal power and that achievable in nominal condition operation. For the latter, design evaluations on the two simulated edifices have allowed to identify a nominal thermal power of $14 \mathrm{~kW}$ (assuming a suitable contemporary factor for heating and DHW) for the single-storey building and of $20 \mathrm{~kW}$ for the double-storey building. Finally, the non-renewable primary energy was computed by associating a conversion factor of 0.2 for the energy input of the biomass boiler and again of 1.95 for the electricity absorbed from the grid.

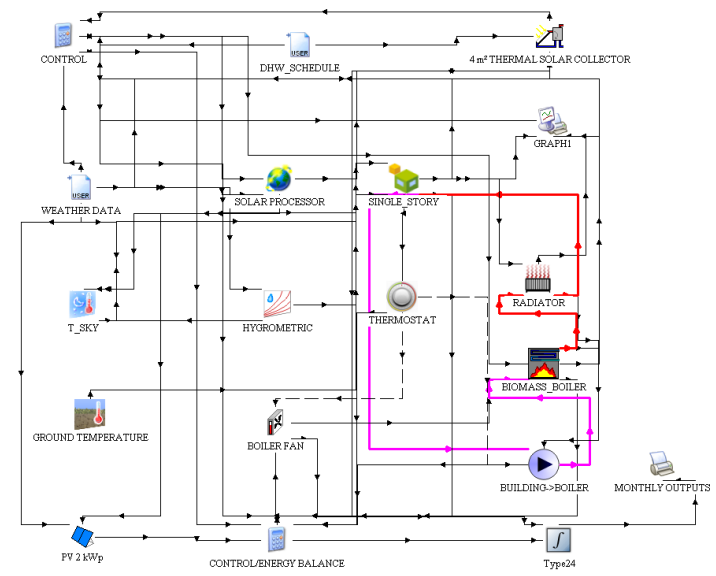

Fig. 5 - Project implemented in the TRNSYS interface for the building-plant system with the biomass boiler

\subsection{Non-renewable energy share with the quasi-steady approach}

Currently, the Italian building energy standard requires the calculation of the heating energy requirements, which are determined at a monthly level by the quasi-steady approach that uses the concept of heat gain utilization factor and a mono-capacitive building model to take into account the transient phenomena. Successively, the primary energy requirements are calculated by applying 5 efficiency values that consider the thermal losses in the heating plant (production, storage, distribution, regulation and emission) by separating the fossil and renewable shares with an apposite conversion factor. A similar approach is used for the estimation of the primary energy demand for DHW production. When heat pumps are involved as generation system, the energy input (electric energy) is determined with the quasidynamic BIM method [27], whereas the thermal efficiency of the boiler at monthly level is calculated by referring to three different operation mode (full load, partial load, and null load) in accordance to the Directive 92/42/CEE procedure [28]. Finally, PV production is determined by introducing a correction coefficient to consider the module ventilation and the effects due to the cell's thermal drift, as well as BOS efficiency. Furthermore, the energy standard considers the whole PV producibility entirely absorbed by the technical plants (except for the devices operating with the sole Joule effect) by assuming the employment of an ideal electric storage system. 


\section{RESULTS}

In Fig. 6, with reference to the single-storey building $(\mathrm{S} / \mathrm{V}=0.75)$, the yearly non-renewable primary energy per square meter of heated net surface (non-renewable Energy Performance index, EP $\left[\mathrm{kWh} / \mathrm{m}^{2}\right]$ ) is depicted as a function of the considered HDD and, only for the heating plant equipped with the AWHP, of the PV size. It is clear that, despite the augment of the envelope insulation level with the HDD growth, the fossil share increases with the number of HDD due to the prolonged employment of the generation system and the unfavorable outdoor air temperatures. However, for the single-storey building, the performances of the AHWP assisted by the PV generator are always better than the biomass boiler, indicating that the magnitude of the electricity absorbed from the grid is not in such amount to be affected excessively by the penalizing conversion factor in fossil primary energy. Furthermore, it is worth noting that the increase of the PV size does not produce an evident limitation of the primary fossil demand. Indeed, the precise and instantaneous electric energy balance carried out by TRNSYS has highlighted that, in every climatic zone and in continuos functioning conditions, the thermal storage system and its control strategy are not sufficient to relieve the mismatching between PV production and thermal load request. In particular, greater heating loads are required prevalently at night, with a quick discharge of the storage system, and consequent activation of the AWHP that uses electricity from the grid. The slight reduction of the fossil primary energy share with the PV size growth is essentially due to the wider availability of renewable electricity during the AHWP and the WHHP operation that in some circumstances allows for limiting the electricity absorbed from the grid.

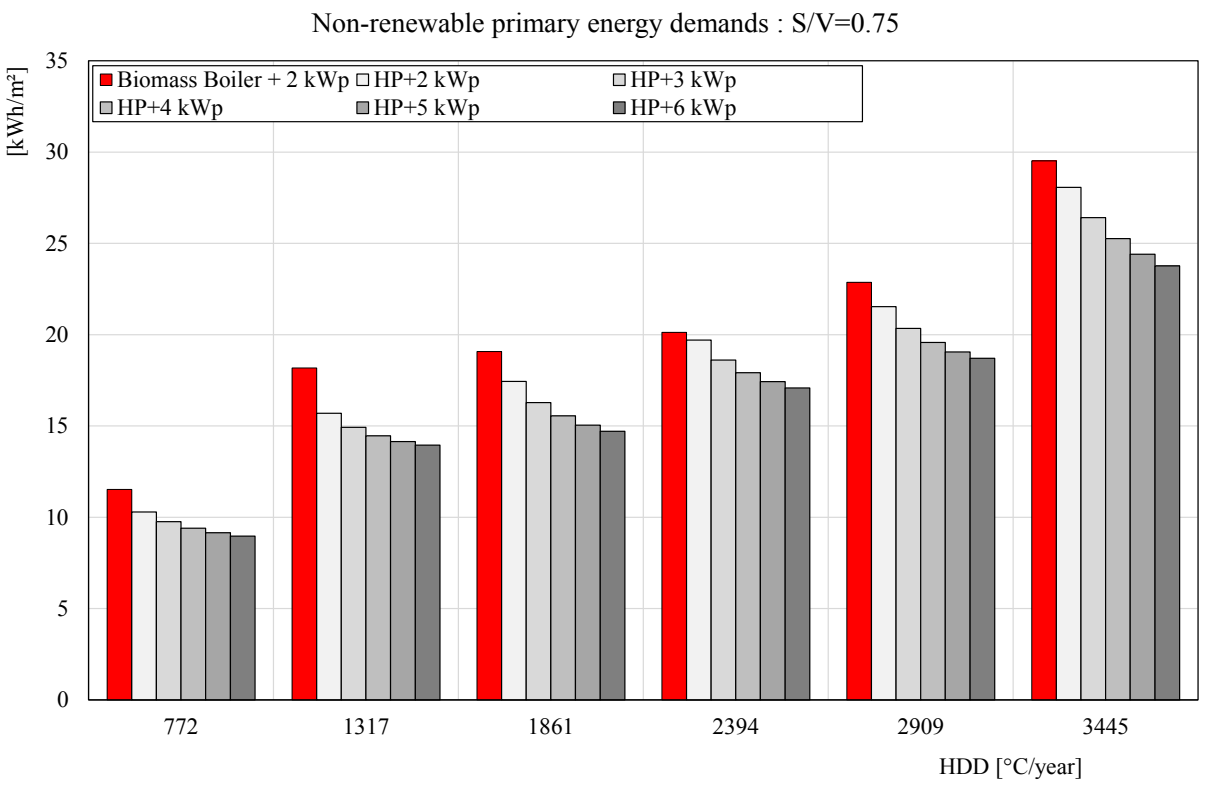

Fig. 6 - Single-storey building: fossil primary energy per square meter of net heated surface as function of the HDD number and for the different heating plant configurations

A different situation was detected instead for the double-storey building ( $\mathrm{S} / \mathrm{V}=0.625)$, which requires more thermal energy to maintain the indoor set-point temperature and for the DHW production. In this case, the employment of the biomass boiler can be suggested rather than other heating plant configurations equipped with the AHWP, as depicted in Fig. 7. In particular, it appears that the biomass boiler becomes more performant when the HDD number increases; this is due to the higher electric consumption of the heat pumps for the greater thermal requirements in colder zones [29]. Therefore, in such severe climates, it is difficult for the assisted AWHP to compete with the biomass boiler. On the contrary, from the same graph, it is possible to appreciate that larger PV peak powers allow for counterbalancing the gap with the biomass boiler when the climatic zone is favorable. Nevertheless, this aspect is not always true because the nonrenewable primary energy depends strongly on the combination of weather data and building-plant features, as demonstrated by the location with 1317 HDD in which the heating plant equipped with the AWHP can be used rationally with every PV size. Nevertheless, the detected trends suggest to prefer biomass boilers especially in the locations with high HDD, whereas in more favorable climatic contexts the gap can be recovered with AWHP by properly increasing the PV size. It is worth noting that, in comparison with the single-storey building, the smaller EPs are due to the smaller building aspect ratio: in fact, the doubling of the heated volume does not correspond with the doubling of the dispersing surface. 
Non-renewable primary energy demands : $\mathrm{S} / \mathrm{V}=0.625$

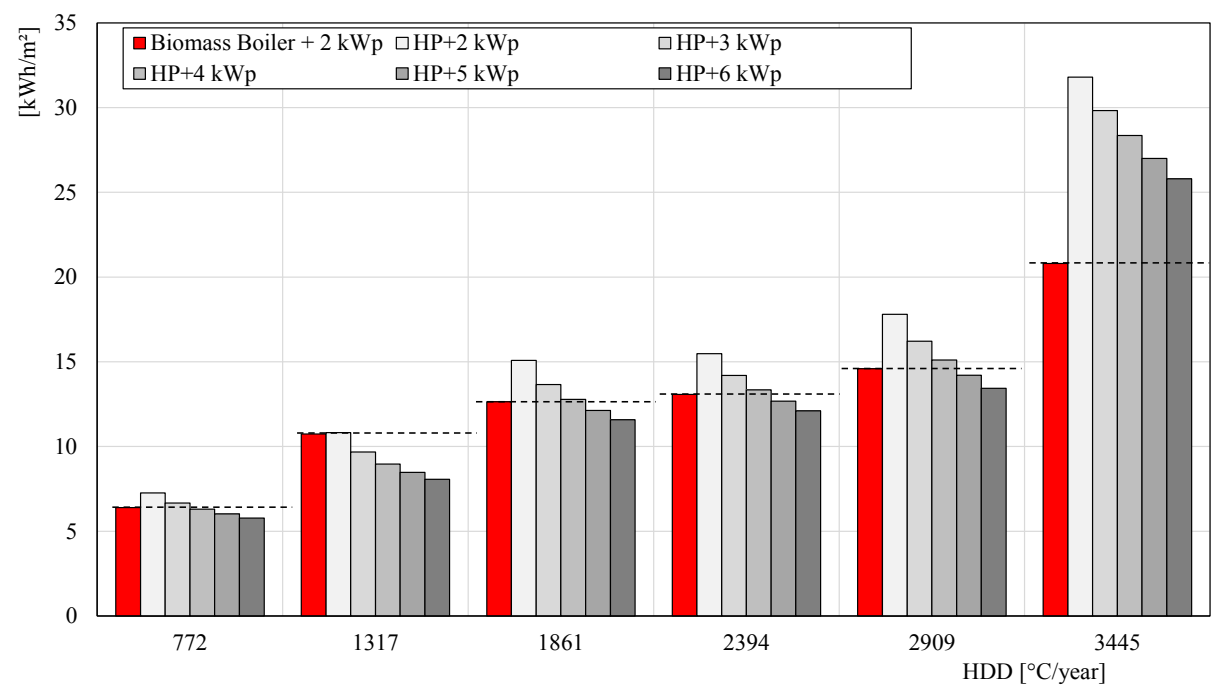

Fig. 7 - Double-storey building: fossil primary energy per square meter of net heated surface as a function of the HDD number and for the different heating plant configurations

The same evaluations conducted on the double-storey building were repeated by adopting the quasi-steady calculation, in accordance to the standard currently employed in Italy for the building energy certification (Fig. 8). The differences in results are obviously due to the different approaches used to determine the thermal and primary energy requirements, however, it is clear the evident simplification to consider the whole PV producibility completely used to satisfy heating and DHW requirements in the quasi-steady approach. Indeed, this hypothesis produces fossil primary energies that reduce linearly with the PV size and, for the location with 3445 HDD, the AWHP assisted by a $6 \mathrm{~kW}_{\mathrm{p}}$ PV generator offers an EP lower than the one detected for the biomass boiler, in contradictory with the results highlighted in Fig. 7. Therefore, considering the whole PV production instead of the actual self-consumed PV electricity produces a very different scenarios in presence of large PV surfaces that do not reflect the actual energy balance of the building-plant system.

The results reported in Fig. 6 and Fig. 7 give information concerning the energy performance worsening of the heat generator systems prevalently due to the outdoor temperature reduction observable with the HDD growth, whereas the same results are independent of the PV performances due to similar producibility among the considered locations. For this reason, in order to define the role of the PV producibility on the AWHP performances, further dynamic simulations have been carried out by considering two localities with different latitudes but similar HDD. In particular, the EPs were determined as a function of the PV size for the location with 3445 HDD considered in the previous evaluations (Lat. 41 ${ }^{\circ} \mathrm{N}$ ) and another location with $3452 \mathrm{HDD}$ but with a higher latitude (about $45^{\circ} \mathrm{N}$ ). The results showed in Fig. 9 for the double-storey building demonstrate the important role of the PV production, with an EP worsening detected when moving toward higher latitudes. In particular, these results are due to the limited availability of solar radiation that determines deviances of non-renewable energy ranging between 5.7 and $8.2 \mathrm{kWh} / \mathrm{m}^{2}$; whereas at a seasonal level the available aerothermal energy can be considered similar due to the equivalent HDD of the two localities. For the same reason, the PV cell thermal drift effects are comparable and do not contribute to the PV producibility, affected exclusively by the limited availability of solar radiation. It is worth noting that the gap tends to reduce with the PV size growth, by confirming that the differences in terms of solar radiation can be recovered by increasing the caption surface because the probability to meet PV production and thermal load request increases. 
Non-renewable primary energy demands : $\mathrm{S} / \mathrm{V}=0.625$

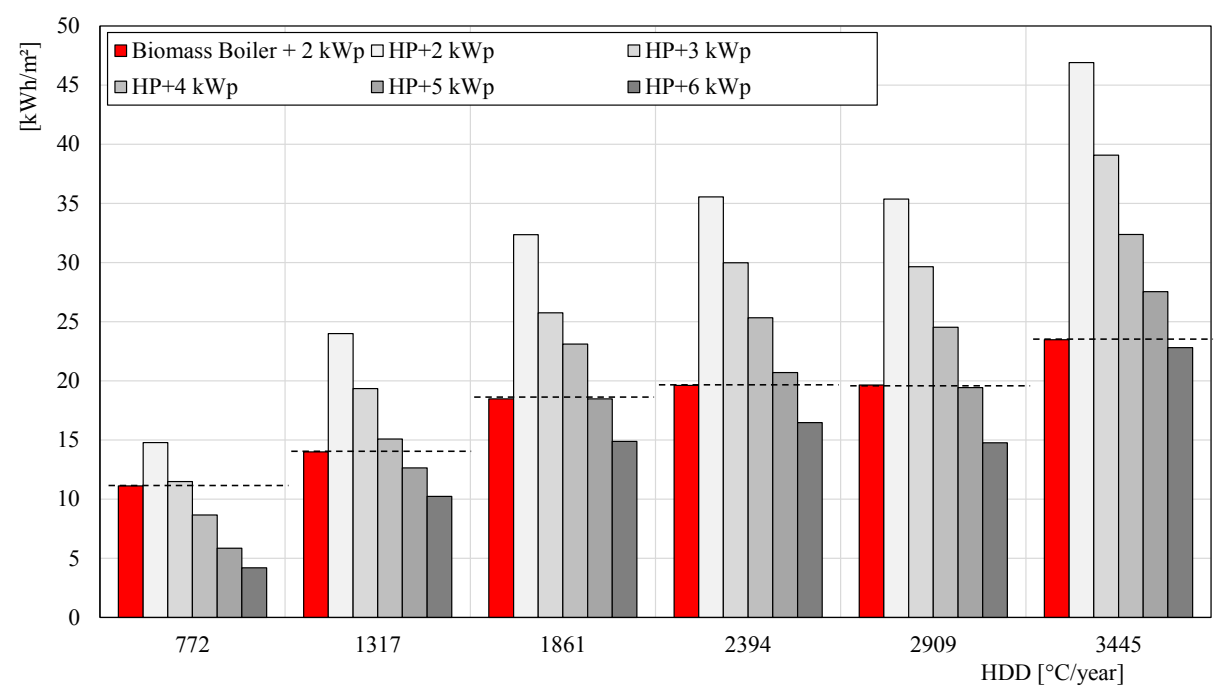

Fig. 8 - Double-storey building: fossil primary energy per square meter of net heated surface as a function of the HDD number and for the different heating plant configurations determined with the quasi-steady model

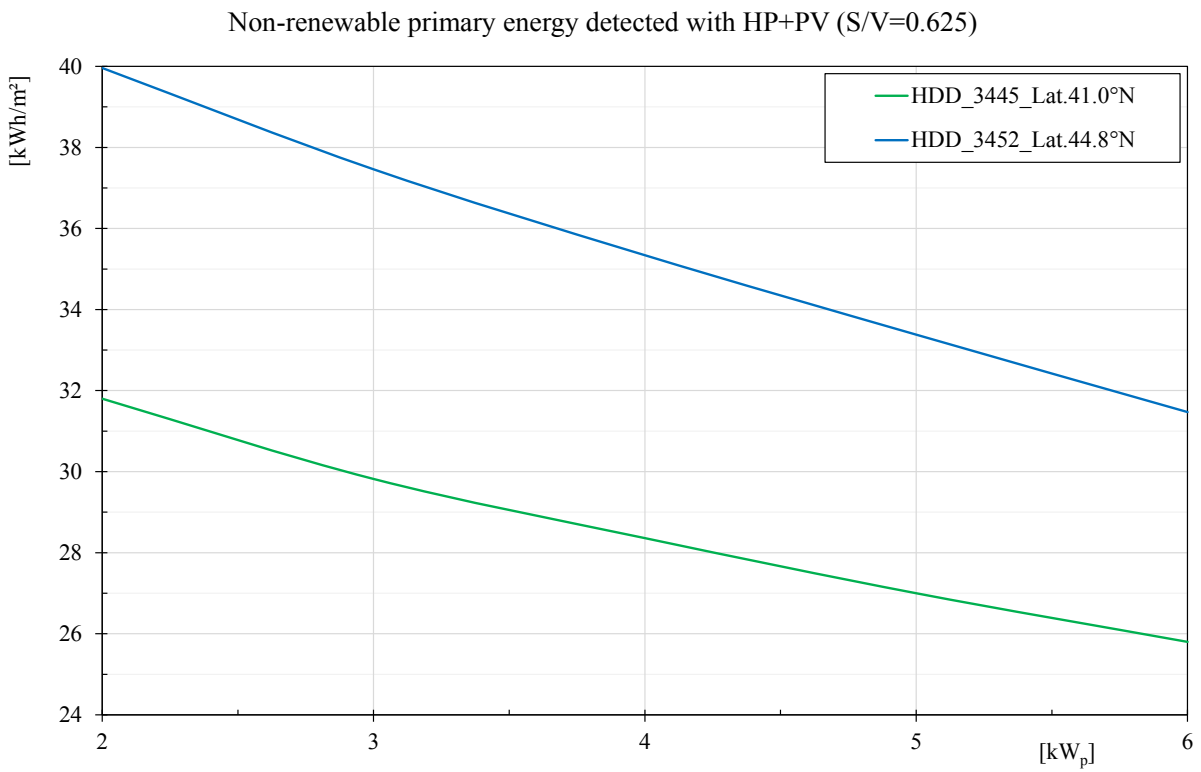

Fig. 9 - Double-storey building: fossil primary energy per square meter of net heated surface as a function of the PV size for two localities with similar HDD 
The analysis conducted has demonstrated that the role of the self-consumed PV electricity is decisive to attain the share of primary renewable energy employed to satisfy heating and DHW production requirements. Nevertheless, the increase of the self-consumed PV electricity share does not mean necessarily a preference for the heat pump systems. Fig. 10 shows the monthly values of self-consumed PV electricity (in $\mathrm{kWh}_{\mathrm{el}}$ per square meter of heated surface), with the correspondent percentage referred to the PV production for the single and double-storey buildings for the locality with 3445 HDD assuming a PV peak power of $6 \mathrm{~kW}_{\mathrm{p}}$. It can be noticed a greater self-consumed share for the double-storey building, especially in the coldest months, concluding that the greater operation of the heat pumps systems led to better exploitation of the PV generator. Nevertheless, in light of the results in Fig. 7, still, the renewable primary energy shares are worse than those detected for the biomass boiler, meaning that the remaining part absorbed from the grid assumes a prevalent role in the fossil primary consumptions forming. Therefore, it is confirmed that heat pump systems are preferable in presence of contained energy consumptions, even with the thermal storage system, and consequently in severe climatic zones is mandatory to limit as possible the thermal energy requirements in buildings. Moreover, it can be appreciated how the self-consumed PV electricity ranges between a maximum value of $48.6 \%$ in December and minimum values around $0.5-1 \%$ in summer, assuming a mean seasonal percentage of $9.4 \%$ and $26 \%$ for the single and the doublestorey respectively.

In order to investigate how to increase the self-consumed PV electricity, in Fig. 11 for the single-storey building equipped with the heat pumps and for the locality with $1861 \mathrm{HDD}$, the non-renewable energy shares were determined by assuming a heating plant functioning closer to the actual conditions. In particular, in such locality, the indoor set-point temperature can be $20^{\circ} \mathrm{C}$ for a maximum of 12 hours per day, as listed in the schedule of Tab.4, whereas in the remaining part of the day an attenuation operation mode was simulated by supplying the radiant floors at a temperature of $25^{\circ} \mathrm{C}$. Furthermore, a PV peak-power of $6 \mathrm{~kW}_{\mathrm{p}}$ was set.

Tab. 4 - Time slots of the indoor set-point temperatures for the calculation of the primary energy requirements in the considered buildings assuming a non-continuous operating regime of the heating plant

\begin{tabular}{|c|c|c|c|c|c|c|}
\hline \multicolumn{7}{|c|}{ Indoor set-point temperature $\left[{ }^{\circ} \mathrm{C}\right]$} \\
\hline 00:00-06:00 & $\begin{array}{c}06: 00- \\
10: 00\end{array}$ & $10: 00-12: 00$ & $\begin{array}{c}12: 00- \\
15: 00\end{array}$ & $15: 00-17: 00$ & $\begin{array}{c}17: 00- \\
22: 00\end{array}$ & $22: 00-00: 00$ \\
\hline Attenuated & $20^{\circ} \mathrm{C}$ & Attenuated & $20^{\circ} \mathrm{C}$ & Attenuated & $20^{\circ} \mathrm{C}$ & Attenuated \\
\hline
\end{tabular}

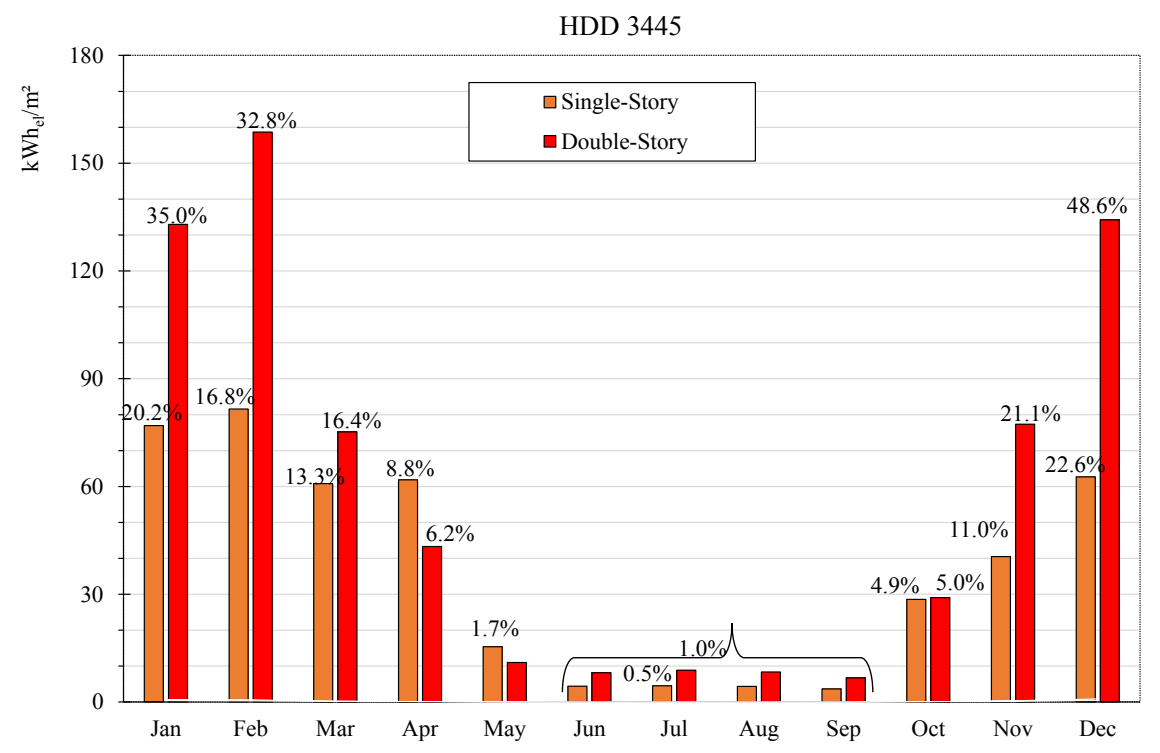

Fig. 10 - Self-consumed PV electricity and percentage value referred to the monthly producibility for the two buildings located in the locality with $3445 \mathrm{HDD}$ equipped with a PV generator of $6 \mathrm{~kW}_{\mathrm{p}}$

It is worth noting that the new management of the heating plant, and especially of the storage system, leads to better use of the PV generator because the mean seasonal percentage of the self-consumed electric energy increases from $9.7 \%$ of the base case up to $19.9 \%$ of the actual scenario. This allows for achieving a better Energy Performance index that 
reduces from $14.71 \mathrm{kWh} / \mathrm{m}^{2}$ of the base case down to $12.33 \mathrm{kWh} / \mathrm{m}^{2}$. Nevertheless, despite the self-consumed PV electricity doubled, the non-renewable primary energy improvement is limited because it reduces of about $137 \mathrm{kWh}$. This means that the building energy performances continue to be strongly penalized by the high conversion factor in fossil primary energy despite the electricity absorbed from the grid was reduced.

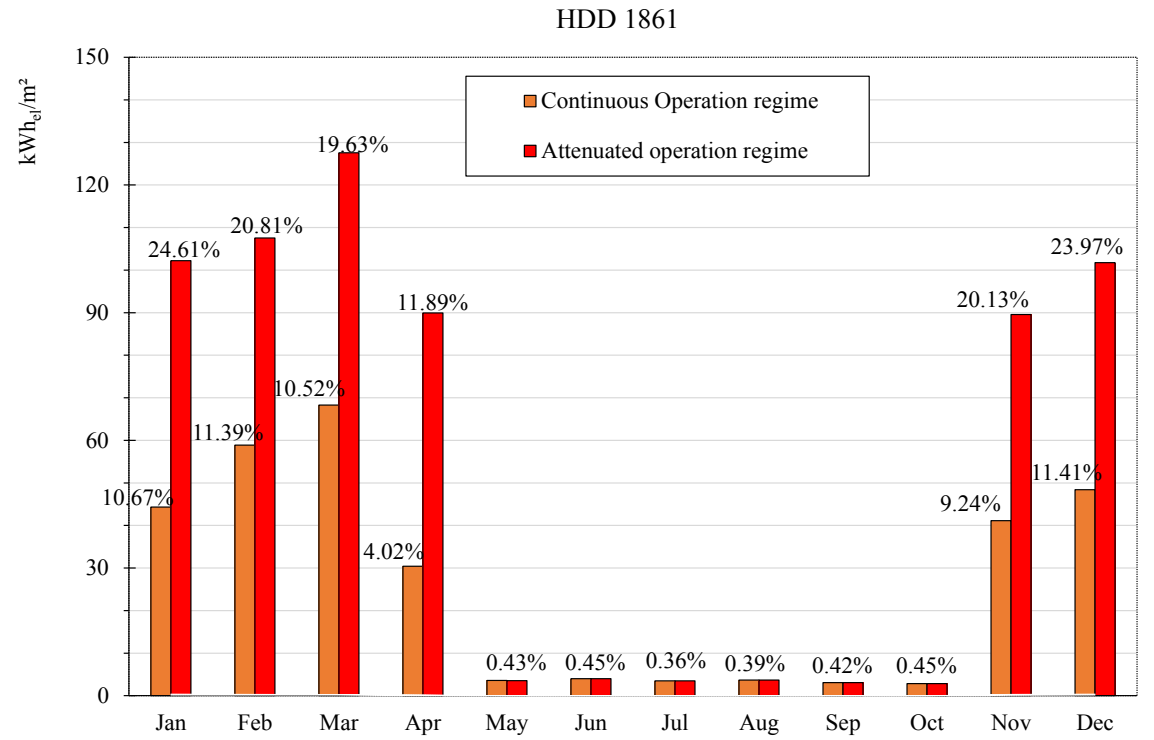

Fig. 11 - Self-consumed PV electricity and percentage value referred to the monthly producibility for the single-storey buildings located in the locality with $1861 \mathrm{HDD}$ equipped with a PV generator of $6 \mathrm{~kW}_{\mathrm{p}}$ and assuming a continuous and an attenuation operation regime of the heating plant

\section{CONCLUSION}

In this paper, the non-renewable shares of two different heat generator systems, represented by a boiler supplied by solid biomass and connected to high-temperature emitters and a PV assisted air-water heat pump supplying radiant floors, were calculated in a transient regime by considering different HDD and by varying the size of the PV generator. The nonrenewable share includes also the primary energy required for the DHW production, obtained in a combined manner with the biomass boiler and with an independent water heater heat pump in presence of PV assisted heat pumps. Finally, two typologies of buildings were simulated and designed in order to meet the minimum energy requirements required by Italian legislation. The same calculation has been repeated adopting the quasi-steady model in order to highlight the deviances when the energy certification procedure is carried out. The results can be summarized as follow:

- $\quad$ assisted air-water heat pumps offer better performances in buildings with reduced thermal energy needs because the electricity from grid is limited. Consequently, the share of fossil primary energy is reduced despite the employment of the highest conversion factor among the energy carriers;

- with the increase of the building thermal energy demands and with the HDD growth, biomass boilers produce better results because the electric energy from the grid becomes significant, furthermore the non-renewable share is further penalized by low outdoor air temperatures that penalize the COP increasing the electric consumptions;

- $\quad$ whit limited HDD, the gap between biomass boilers and heat pumps can be recovered easily by increasing the PV generator size;

- the results obtained with the quasi-steady approach show a different scenario because the PV electricity is considered completely absorbed from heating and DHW devices. Dynamic simulations, instead, showed an evident winter mismatching between solar radiation availability and thermal load request, still difficult to solve by adopting thermal energy storage systems, even if managed by suitable control strategies;

- $\quad$ at parity of climatic zone, the renewable shares determined with heat pumps are strongly affected by the locality latitude due to the different PV producibility. By augmenting the caption surface, a self-consumed PV electricity growth was observed because the probability to meet PV production and thermal load request increases.

- by assuming continuous functioning condition and despite the priority of the PV production was given to the generation systems, it was difficult to assess PV self-consumed electricity greater than $50 \%$. Nevertheless, these percentages improve with the thermal energy requirements increase and with the PV size growth. 
- $\quad$ in attenuated functioning conditions, the PV self-consumed electricity increases due to a better exploitation of the thermal storage tank.

Globally, in cold climates biomass are recommended to increase the shareof the renewable primary energy. PV assisted heat pumps are negatively affected by lower COP detectable in localities with high HDD, which requires a larger use of the electricity from the grid, especially at night. Since localities with high HDD numbers usually do not require cooling, the advantage to use the same heat pumps in summer fails. Conversely, climatic zones with high HDD are generally located in mountainous regions where there is a wider availability of solid biomass, making these devices able to exploit "local" fuel. The thermal storage systems managed by appropriate control strategies can improve the heat pump performance in favorable climates, however, a suitable PV size has to be installed. Nevertheless, to contrast the issues related to the aleatory nature of the renewable source and the misalignment with the building thermal loads, a great role could be assumed by the energy communities assuming the building-plant system able to rationalize the energy produced in-situ by exchanging thermal and/or electric energies with other structures, making heat pumps more competitive.

\section{References}

1. I. E. A. IEA, Data and Statistics, Https://Www.Iea.Org/Data-and-Statistics, Accessed on 15th June 2021 (2021)

2. European Commission, Directive 28/2009 of the European Parliament and of the Council of 23 April 2009on the Promotion of the Use of Energy from Renewable Sources and Amending and Subsequently Repealing Directives 2001/77/EC and 2003/30/EC (2009), p. L 140/16-62

3. European Commission, Directive (EU) 2018/844 of the European Parliament and of the Council of 30 May 2018 Amending Directive 2010/31/EU on the Energy Performance of Buildings and Directive 2012/27/EU on Energy Efficiency (2018), pp. 1-17

4. N. Aste, P. Caputo, C. Del Pero, G. Ferla, H. E. Huerto-Cardenas, F. Leonforte, and A. Miglioli, Energy 206, (2020)

5. N. Arcuri, R. Bruno, and C. Carpino, in 2018 IEEE Int. Conf. Environ. Electr. Eng. 2018 IEEE Ind. Commer. Power Syst. Eur. (EEEIC / I\&CPS Eur. (IEEE, 2018), pp. 1-6, doi:10.1109/EEEIC.2018.8493492

6. $\quad$ Arcuri N., Bruno R., Bevilacqua P., Carpino C., in BS2019 - Build. Simul. Assoc. Rome Conf. (2017)

7. M. Carpio, M. Zamorano, and M. Costa, Energy Build. 66, 732 (2013)

8. Italian iterministerial decree 26th June 2015: Application of calculation methods for energy performance and definition of minimum building requirements, Off. Gazzette Ital. Repub. N³9 15th July 20151 (2015)

9. R. Bruno, F. Nicoletti, G. Cuconati, S. Perrella, and D. Cirone, Energies 13, (2020)

10. T. Olkowski, S. Lipiński, and A. Olędzka, E3S Web Conf. 19, (2017)

11. J. A. Lozano Miralles, R. López García, J. M. Palomar Carnicero, and F. J. R. Martínez, Renew. Energy 152, $1439(2020)$

12. M. J. Stolarski, M. Krzyzaniak, K. Warmiński, and D. Niksa, Energy Convers. Manag. 121, 71 (2016)

13. A. Saari, T. Kalamees, J. Jokisalo, R. Michelsson, K. Alanne, and J. Kurnitski, Appl. Energy 92, 76 (2012)

14. B. Hebenstreit, R. Schnetzinger, R. Ohnmacht, E. Höftberger, J. Lundgren, W. Haslinger, and A. Toffolo, Biomass and Bioenergy 71, 12 (2014)

15. VV.AA., TRNSYS Libr. Vol. 4 Math. Ref. Sol. Energy Lab. Univ. Wisconsin-Madison, USA (2016)

16. Italian Unification Institution, UNI TS 11300-1: Energy Performance of Buildings - Part 1: Evaluation of Energy Need Far Space Heating and Cooling (2014)

17. Italian Unification Institution, UNI 11300-2: Energy Performances of Buildings- Part 2- Evaluation of Primary Energy Need and of System Efficiency for Space Heating, Domestic Hot Water Production, Ventilation and Lighting for Non-Residential Buildings (2014), pp. 37-40

18. Italian Unification Institution, UNI TS 11300-4. Energy Performances of Building: Renewable Energy and Other Generation Systems for Space Heating and Domestic Hot Water Production (2016)

19. TRANSSOLAR \& Energietechnik GmbH, TRNSYS Doc. (2016)

20. J. Szyszka, Energies 13(3), (2020)

21. B. Gil, S. Rosiek, J. Kaspersky, M. Nems, A. Nems, ECOS 2019 - Proceedings of the 32nd International Conference on Efficiency, Cost, Optimization, Simulation and Environmental Impact of Energy Systems, pp. 2559-2570,

22. G. Evola and L. Marletta, Energy and Buildings 65, pp. 448-457 (2013)

23. M. Cucumo, V. Ferraro, D. Kaliakatsos, M. Mele, Energy and Buildings 158, pp. 677-683, (2018)

24. R. Bruno, P. Bevilacqua, L. Longo, and N. Arcuri, in Energy Procedia (2015)

25. P. Bevilacqua, R. Bruno, and N. Arcuri, Energy 195, 116950 (2020)

26. EN 14825:2018, Air conditioners, liquid chilling packages and heat pumps, with electrically driven compressors, for space heating and cooling - Testing and rating at part load conditions and calculation of seasonal performance

27. M. Dongellini, C. Naldi, G.L. Morini, Applied Thermal engineering 90, (2015)

28. European Commission, Directive 92/42/EEC of the European Parliament and of the Council of 21 May 1992 on efficiencyrequirementsfornewhot-waterboilersfiredwithliquidorgaseousfuel, p. L 167/17

29. S. Korol, N. Shushunova, T. Shushunova, MATEC Web of Conferences, Volume 193, Article Number 05075 